\title{
Environmentally clean micromilling of electron beam melted Ti6Al4V
}

\author{
Bruschi, S.; Tristo, G.; Rysava, Z.; Bariani, P. P.; Umbrello, D.; De Chiffre, Leonardo
}

Published in:

Journal of Cleaner Production

Link to article, DOI:

10.1016/j.jclepro.2016.06.035

Publication date:

2016

Document Version

Peer reviewed version

Link back to DTU Orbit

Citation (APA):

Bruschi, S., Tristo, G., Rysava, Z., Bariani, P. P., Umbrello, D., \& De Chiffre, L. (2016). Environmentally clean micromilling of electron beam melted Ti6Al4V. Journal of Cleaner Production, 133, 932-941.

https://doi.org/10.1016/j.jclepro.2016.06.035

\section{General rights}

Copyright and moral rights for the publications made accessible in the public portal are retained by the authors and/or other copyright owners and it is a condition of accessing publications that users recognise and abide by the legal requirements associated with these rights.

- Users may download and print one copy of any publication from the public portal for the purpose of private study or research.

- You may not further distribute the material or use it for any profit-making activity or commercial gain

- You may freely distribute the URL identifying the publication in the public portal

If you believe that this document breaches copyright please contact us providing details, and we will remove access to the work immediately and investigate your claim 


\section{Accepted Manuscript}

Environmentally clean micromilling of electron beam melted Ti6Al4V

S. Bruschi, G. Tristo, Z. Rysava, P.F. Bariani, D. Umbrello, L. De Chiffre

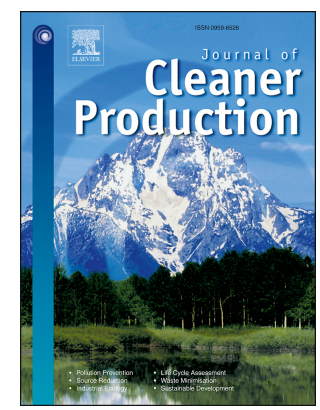

PII: S0959-6526(16)30710-7

DOI: $\quad$ 10.1016/j.jclepro.2016.06.035

Reference: JCLP 7406

To appear in: Journal of Cleaner Production

Received Date: 14 May 2015

Revised Date: 21 April 2016

Accepted Date: 5 June 2016

Please cite this article as: Bruschi S, Tristo G, Rysava Z, Bariani PF, Umbrello D, De Chiffre L, Environmentally clean micromilling of electron beam melted Ti6Al4V, Journal of Cleaner Production (2016), doi: 10.1016/j.jclepro.2016.06.035.

This is a PDF file of an unedited manuscript that has been accepted for publication. As a service to our customers we are providing this early version of the manuscript. The manuscript will undergo copyediting, typesetting, and review of the resulting proof before it is published in its final form. Please note that during the production process errors may be discovered which could affect the content, and all legal disclaimers that apply to the journal pertain. 


\title{
ENVIRONMENTALLY CLEAN MICROMILLING OF ELECTRON BEAM MELTED TI6AL4V
}

\author{
S. Bruschia, G. Tristoa , Z. Rysava ${ }^{a}$, P.F. Bariania , D. Umbrellob, L. De Chiffre ${ }^{c}$ \\ a Department of Industrial Engineering, University of Padova, Via Venezia 1, 35131 Padova, Italy \\ stefania.bruschi@unipd.it \\ paolo.bariani@unipd.it \\ gianluca.tristo@dii.unipd.it \\ zdenka.rysava@studenti.unipd.it
}

b Department of Mechanical, Energy and Management Engineering, University of Calabria, Via P. Bucci Edificio Cubo 46 C 87036 Arcavacata di Rende (CS), Italy

domenico.umbrello@unical.it

c Department of Mechanical Engineering, Technical University of Denmark, Nils Koppels Allé Building 404 DK-2800 Kgs. Lyngby, Denmark

$\underline{\text { ldch@mek.dtu.dk }}$

\begin{abstract}
The paper is aimed at evaluating the performances of Minimum Quantity Lubrication (MQL), dry cutting and cryogenic cooling when applied to the micro-milling of Ti6Al4V titanium alloy samples obtained by Additive Manufacturing (AM) using the Electron Beam Melting (EBM) technology. The micro-milling tests were carried out on a high precision 5-axis micro-milling center, at varying cutting speed and feed per tooth. The performances of the different lubrication/cooling strategies were analyzed in terms of surface integrity, namely surface topography, nano-hardness and sub-surface microstructural alterations, in order to prove the impact of clean cutting conditions when applied to micro-machining of a AM titanium alloy of biomedical interest. It is shown that dry cutting assures the same performances of MQL, representing then the most suitable option to decrease the environmental impact of the machining process.
\end{abstract}

\section{Keywords}

Ti6Al4V, Micro-milling, MQL, Dry, Cryogenic, Surface integrity

\section{Introduction}

The increasing ageing of population affects different aspects of the healthcare, being the surgery related to first implantation and/or replacement of implants one of the most challenging. On a global scale, the number of operations is in the order of millions every year (Murr et al., 2009). In the recent years, Additive Manufacturing (AM) technologies are increasingly being adopted in the biomedical field for the production of parts made of titanium alloys (Bartolo et al., 2012) -especially the Ti6Al4V - thanks to the chance they offer to realize complex geometrical features - even internal cavities - in just few manufacturing steps, thus reducing the manufacturing process chain, compared to the traditional process chain that generally includes forging at elevated temperature, roughing, semi-finishing, finishing, polishing and heat treatment; whereas, in the case of using AM, only semi-finishing or finishing machining steps can be needed to achieve the required quality, therefore limiting the material waste. AM technologies can also give an answer to the increasing demand of micro-sized implants and surgical instruments or parts characterized by micro-sized features, as is the case of dental implants. If, on one hand, the surfaces of an AM product favor particularly bio-characteristics, such as the osseo-integration of implants, on the other hand, semi-finishing and/or finishing machining operations may still be needed on those surfaces that have to undergo subsequent assembly. The investigation of the surface integrity of AM titanium alloys subjected to machining operations is therefore mandatory to guarantee the parts functional performances (Jawahir et al., 2011; Kaynak et al., 2014; Ulutan and Ozel, 2011). However, despite the growing interest in AM parts, scarce records can be found in literature addressing this topic (Bordin et al., 2014), only 
related to conventional machining processes at macro-level, still leaving the field of micro-machining of AM parts completely unexplored, whereas micro-cutting of wrought Ti6Al4V parts has been recently addressed (Özel et al., 2011).

In addition, the biomedical sector targets cleanliness issues achievable only through numerous and time-consuming cleaning steps; the avoidance of cutting fluids during the part manufacturing would limit these steps, thus reducing the cleaning procedure impact. However, the basic function of cutting fluids is to dissipate the heat generated by plastic deformation as well as friction phenomena in the cutting zone (Lawal et al., 2013; Li and Chou, 2010; Marcon et al., 2010; Sarıkaya and Güllü, 2015; Vazquez et al., 2015), which, in turn, helps in increasing the tool life, besides removing the chips from the cutting zone, improving the dimensional accuracy and surface quality and also limiting the burrs formation (Lawal et al., 2013; Li and Chou, 2010; Marcon et al., 2010; Sarıkaya and Güllü, 2015; Vazquez et al., 2015). On the other hand, cutting fluids represent a significant cost issue in the whole machining process, up to $17 \%$ of the total process cost (Lawal et al., 2013; Li and Chou, 2010; Vazquez et al., 2015), in addition to the costs for their disposal (Sarıkaya and Güllü, 2015). Among all the different concerns, the cutting fluids are considered the most prominent environmental issue for machining processes. Nowadays, cutting fluids have changed dramatically due to recent regulations on environment, health and safety issues, which identify some of the ingredients in cutting fluids as hazardous. In fact, the detection of a variety of illnesses and environmental hazards these ingredients cause has forced their reduced use, or even their elimination. Characteristics as biodegradability, toxicity, renewability, bioaccountability, biomagnifications have to be taken into account more and more as a consequence of the stringent environmental regulations (Debnath et al., 2014). Several researchers have carried out investigations aimed at classifying the potential hazards of the cutting fluids and their effects on the human body (Munoz and Sheng, 1995) and the toxicity levels, especially as a consequence of dermal and inhalation exposures. As an example, $80 \%$ of the operators' infections is due to the skin contact with the fluids that are irritant, allergic and can be carcinogen (skin cancer lung cancer) (Debnath et al., 2014). In general, the delivered cutting fluids delivered are oil-based, which are more responsible for significant environmental pollution and whose storage and disposal are more hazardous than aqueous-based and gas-based cutting fluids. Just in the countries of the EU some hundreds of Mt of cutting fluids are used every year and about 2/3 of this amount has to be disposed, being $85 \%$ of all the used cutting fluids mineral oils (Debnath et al., 2014). Moreover, the costs associated to the disposal of cutting fluids based on mineral oils are remarkably high as they are not biodegradable and the related post-use treatments are complicated and expensive, ranging between 24 times of their purchase cost (Debnath et al., 2014; Shokrani et al., 2012). In case of micro-milling, Minimum Quantity Lubrication (MLQ) is usually applied, in form of a mist where the cutting fluid is provided in tiny quantities, in the order of about ten-thousandth of the amount of cutting fluid in conventional flood lubrication. MLQ is generally considered to be an emission-free process thanks to the drastic reduction of cutting fluid use compared to conventional flood lubrication, nevertheless, the oil present in the MQL mist may decompose and produce pyrolysis products as a consequence of the cutting temperatures, which may cause major health concerns.

For the above listed reasons, it is of primary importance to define suitable processing routes to manufacture products using more sustainable methods and processes, which could ideally avoid or, at least, minimize the use of cutting fluids during machining, thus providing a healthy and safe working environment, but still maintaining the required process and product performance levels. Furthermore, in doing so, the cleanliness issues of the biomedical sector would be fully addressed.

However, the avoidance of cutting fluids is particularly challenging when machining titanium alloys that are recognized to be difficultto-cut materials being their surface integrity and tool life strongly influenced by the applied lubrication conditions (Vazquez et al., 2015), which may be drastically reduced. In this context, the paper aims at investigating the performances of dry cutting and cryogenic cooling in comparison with the conventionally applied Minimum Quantity Lubrication (MQL), in case of micro-milling applied to the Ti6Al4V titanium alloy fabricated by means of Electron Beam Melting (EBM), an AM technique recently introduced in the biomedical field to produce implants of different sizes. It is worth to underline that the feasibility of adopting cryogenic cooling by using liquid nitrogen was for the first time investigated in micro-milling, on the basis of the wide literature available about cryogenic cooling in conventional machining (Kaynak et al., 2014; Umbrello et al., 2012). The performances of the different cooling and lubrication strategies were assessed and critically discussed in terms of surface integrity of the machined workpieces, namely topography characteristics, surface defects, microstructural state and mechanical properties and its sensitivity to the different lubricating conditions assessed and critically discussed, together with their environmental impact. 


\section{Experimental procedure}

\subsection{Material}

The micro-milling experiments were carried out on samples of Ti6Al4V obtained by Electron Beam Melting (EBM), an AM technique capable of producing full dense parts and widely applied in the biomedical field. The microstructure of an AM metal alloy depends on the initial powder size and morphology, compaction and post thermal processing treatments (Murr et al., 2009); in particular, the typical microstructures obtained by EBM are acicular-type, characterized by fine lamellae, as a consequence of a very fast solidification and subsequent annealing due to the high working zone temperature.

In the as-built condition, the EBM Ti6Al4V samples used in this work presents a microstructure consisting of <alpha>-phase fine lamellae, with an average length less than $5 \mu \mathrm{m}$, organized in a basket wave morphology with $7 \%$ of bcc < beta>-phase in an hcp matrix (see Fig. 1). The acicular microstructure of the EBM Ti6Al4V induces higher tensile strength and hardness, reduced elongation at fracture, and lower fatigue limit in comparison with the wrought alloy that generally shows a globular microstructure(Facchini, 2010; Facchini et al., 2009) (see Table 1); the differences in both the microstructural characteristics and mechanical properties give the EBM alloy a different machinability behavior compared to the wrought one under conventional as well as micro-cutting conditions.

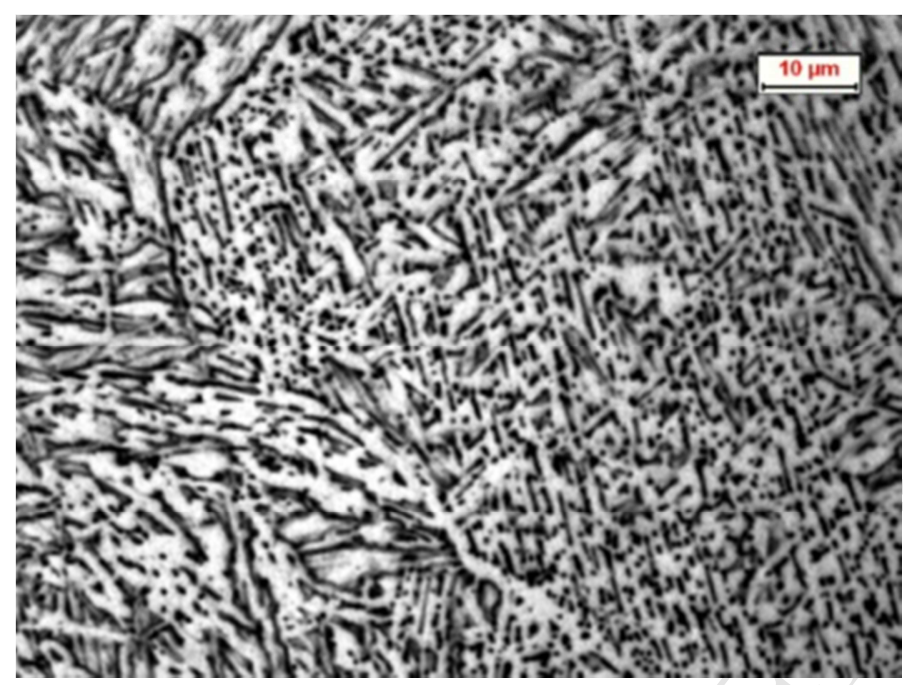

Fig. 1 Microstructure of Ti6Al4V EBM in as-built condition

\begin{tabular}{lll}
\hline & EBM & Wrought \\
\hline Yield strength $\left(\mathrm{R}_{\mathrm{p}} 0.2\right)$ & $950 \mathrm{MPa}$ & $860 \mathrm{MPa}$ \\
\hline Ultimate Tensile Strength $\left(\mathrm{R}_{\mathrm{m}}\right)$ & $1020 \mathrm{MPa}$ & $930 \mathrm{MPa}$ \\
\hline Elongation & $14 \%$ & $>10 \%$ \\
\hline Modulus of elasticity & $120 \mathrm{GPa}$ & $114 \mathrm{GPa}$ \\
\hline
\end{tabular}

Table 1 Mechanical properties of the EBM and wrought Ti6Al4V (Arcam, n.d.)

\subsection{Micro-milling experiments}

30x25x8 mm $\mathrm{mm}^{3}$ workpieces, cut through Wire Electrical Discharge Machining (WEDM) from a cylinder of Ti6Al4V titanium alloy fabricated by EBM process, were used in the micro-milling experiments. Before machining, the top surfaces of the rectangular blocks of EBM Ti6Al4V were flattened, mechanically polished (to remove any possibly affected material layer by the previous WEDM process) and clamped on the machine tool fixture in such a way to have the material layers growing direction parallel to the feed direction.

A Kugler ${ }^{\mathrm{TM}}$ Micromaster 5-axis ultra-precision micro-milling machine was used, equipped with an air bearing spindle suitable for micro-machining up to $180^{\prime} 000 \mathrm{rpm}$, and capable of an all-over positional error of $0.3 \mu \mathrm{m}$ and a maximum linear axis speed of 6'000 $\mathrm{mm} / \mathrm{min}$. The possible thermal expansion of the machine spindle along the $\mathrm{Z}$ axis, which would have impact on the machining accuracy, was controlled in real time by a built-in eddy current sensor, and the related compensation was carried out using the dedicated machine software. 
From the literature it is evident that the simple scaling of the machining process knowledge from the macro- to the micro-scale is not possible and is far from the real experiences (Dornfeld et al., 2006; Kuram and Ozcelik, 2013; Lai et al., 2008). Factors that at the macroscale can be neglected may have a significant effect at the micro-scale, namely the tool edge geometry, microstructure (grain size and orientation), tool deflection, vibrations (Dornfeld et al., 2006; Kuram and Ozcelik, 2013; Lai et al., 2008; Thepsonthi and Özel, 2013, 2012). In micro-cutting, the ratio between the cutting tool edge (usually the cutting edge radius is between 1 and $5 \mu \mathrm{m}$ (Dhanorker et al., 2007; Özel et al., 2011, 2007)) and the uncut chip thickness has to be considered in order to ensure that the shearing process prevails over the ploughing one, both characterizing the material removal in micro-cutting (Dhanorker et al., 2007; Dornfeld et al., 2006).

The scaling issue and the presence of both shearing and ploughing have indeed a great impact on the cutting forces, chip thickness and morphology, surface integrity, burr formations and tool wear (Dhanorker et al., 2007; Dornfeld et al., 2006; Thepsonthi and Özel, 2013). If only ploughing occurs, chips are not formed, leading only to material deformation and a very poor surface quality, as well as to specific cutting energy and tool wear increase (Özel et al., 2011, 2007). The switch from one cutting mechanism to the other is possible through a proper choice of the cutting conditions: when the uncut chip thickness is above the minimum chip thickness, shearing prevails over ploughing. The minimum chip thickness is mainly function of the cutting edge radius, with a secondary effect given by the workpiece material (in multiphase materials it varies as a function of the microstructural constituents (Câmara et al., 2012; Mian et al., 2010)). The ratio between the uncut chip thickness and the cutting edge radius is the critical parameter, being the uncut chip thickness proportional to the feed per tooth.

The full immersion slotting was chosen as machining strategy: in this case the instantaneous chip thickness is function of the rotation angle $\varphi$ and it varies from zero at the beginning of the cutting to its maximum corresponding to the feed per tooth approximately in the middle of the slot and then decreases again to zero. When the uncut chip thickness is smaller than the minimum chip thickness, the chip is not formed, and the cutter must reach certain angle $\varphi$ to create the chip (Dhanorker et al., 2007; Filiz et al., 2007; Özel et al., 2007; Thepsonthi and Özel, 2013). In each test a straight slot, $0.3 \mathrm{~mm}$ wide and $25 \mathrm{~mm}$ long, was machined. The experimental set-up is shown in the Fig. 2. The axial depth of cut was set equal to $30 \mu \mathrm{m}$ and kept constant for the whole experimental campaign. The value of the axial depth of cut was chosen on the basis of the suggestion to use depths of the cut ten times larger than the grain size to minimize the crystallographic effect of the grains during machining (Dornfeld et al., 2006).

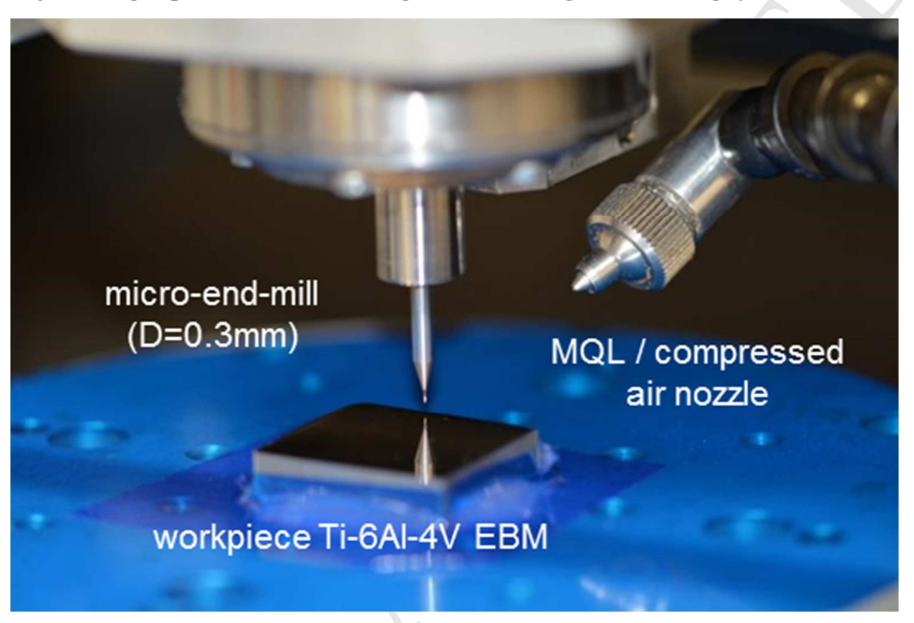

Fig. 2. Experimental set-up

The cutting speed and feed per tooth were varied with two and four levels, respectively, according to a full factorial design, repeating three times each cutting condition. The values of the feeds per tooth were chosen to respect the criterion of the minimum chip thickness. The suitable range of the ratios between the uncut chip thickness and the cutting edge radius is from 0.09 to 0.4 depending on the material and cutting conditions (Afazov and Zdebski, 2013). For the multi-phase metal alloys this ratio is generally between 0.3 and 0.4 , and for Ti- $6 \mathrm{Al}-4 \mathrm{~V}$ was found to be about $0.1-0.2$ (Thepsonthi and Özel, 2013). Furthermore, the combinations of cutting speed and feed per tooth were chosen in order to avoid tool vibrations that would have affected the tests outcomes. Based on the literature 
research and recommended cutting conditions for titanium alloys, different cutting speeds were tested, while acquiring the signal from accelerometers installed in the vertical and radial directions with respect to the spindle axis. These signals were then processed through FFT to verify the vibrations occurrence. The cutting parameters finally employed in the experimental campaign were chosen in such a way to avoid vibrations.

The experimental plan reported in Table 2 was carried out under both dry and lubricated conditions. A jet of compressed air without any cutting fluid was used during the dry experiments in order to cool down both the tool and the workpiece and clear the chips from the cutting area. Isoparafin oil in form of a mist was used as cutting fluid in a regime of Minimum Quantity Lubrication (MQL), with a consumption of $20 \mathrm{ml} / \mathrm{h}$ of oil. To prove the feasibility of the approach, the cryogenic cooling was later on applied only to those dry cutting conditions assuring the best performance in terms of surface integrity.

\begin{tabular}{lllllllll}
\hline $\mathrm{N}[\mathrm{rpm}]$ & \multicolumn{2}{l}{67000} & \multicolumn{5}{l}{154000} \\
\hline $\mathrm{V}_{\mathrm{c}}[\mathrm{m} / \mathrm{min}]$ & 63 & & \multicolumn{5}{c}{145} \\
\hline $\mathrm{f}_{\mathrm{z}}[\mu \mathrm{m} /$ tooth $]$ & 0.1 & 0.5 & 1.5 & 3.0 & 0.1 & 0.5 & 1.5 & 3.0 \\
\hline
\end{tabular}

Table 2. Experimental plan

Liquid nitrogen $\mathrm{LN}_{2}$ was employed to reduce the temperature of the workpiece from room temperature to cryogenic conditions at nearly $-160^{\circ} \mathrm{C}$. In order to limit as much as possible the temperature variations of the tool machine components, while the specimen was reaching the cryogenic conditions, the customized fixture depicted in Fig. 3A was designed and set-up, where only the bottom surface of the workpiece is exposed to the $\mathrm{LN}_{2}$, which is confined into a cryogenic chamber. A layer of polyurethane foam between the external panels and the cryogenic chamber provides the required insulation, limiting as much as possible temperature variations of the machine tool components, during the time interval when the specimen is reaching the cryogenic conditions. The workpiece temperature was controlled through a J-type thermocouple, and a sample constant temperature of $-155 \pm 5^{\circ} \mathrm{C}$ was assured during the machining phase by regulating the $\mathrm{LN}_{2}$ flow (Fig. 3B).

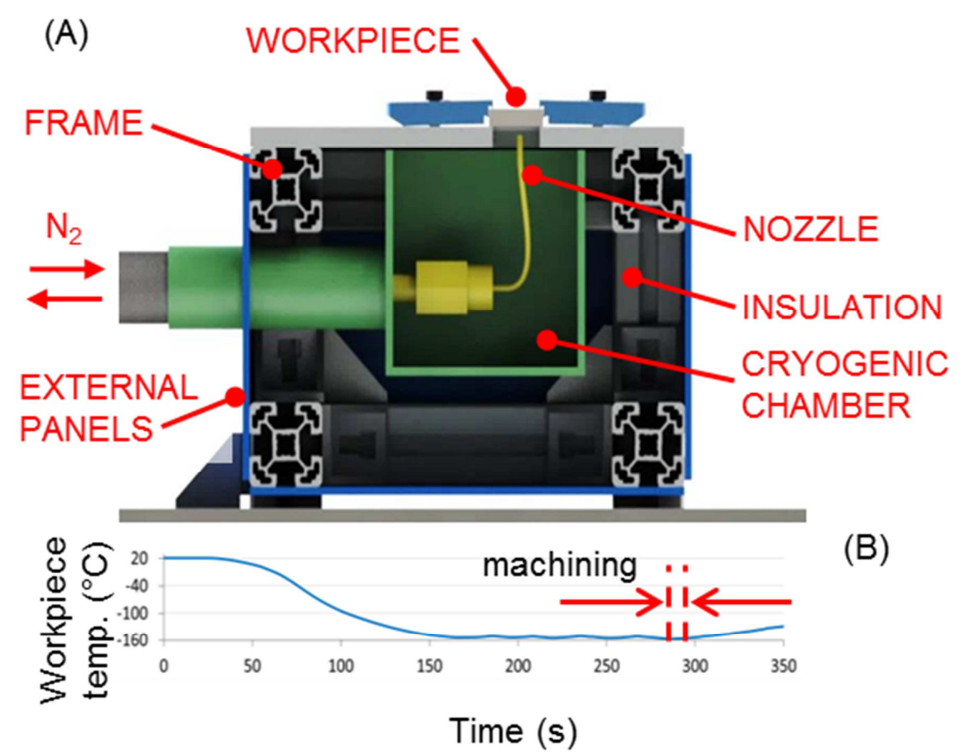

Fig. 3. Set-up of the cryogenic apparatus (A); evolution of the workpiece temperature (B)

Kyocera $^{\mathrm{TM}}$ uncoated flat-end-square two-fluted micro-tools made of tungsten carbide with a diameter of $0.3 \mathrm{~mm}$ were used in the micro-milling experiments. A fresh tool was used for each cutting condition and repetition; before and after each test, the tools were inspected with a FEI ${ }^{\mathrm{TM}}$ Quanta 400 SEM to verify the cutting edges integrity and evaluate the tool state. Fig. 4 shows the cutting edge of a new tool, as received from the tool manufacturer: The edge radius of the fresh tool was measured to be about $1.1 \mu \mathrm{m}$, leading to a critical feed per tooth of $0.33-0.44 \mu \mathrm{m}$ (Liu et al., 2006); therefore, for the investigated feed rate of $0.1 \mu \mathrm{m} /$ tooth, the ploughing mechanism may prevail over shearing and its effect over surface integrity is worthwhile to be investigated. 

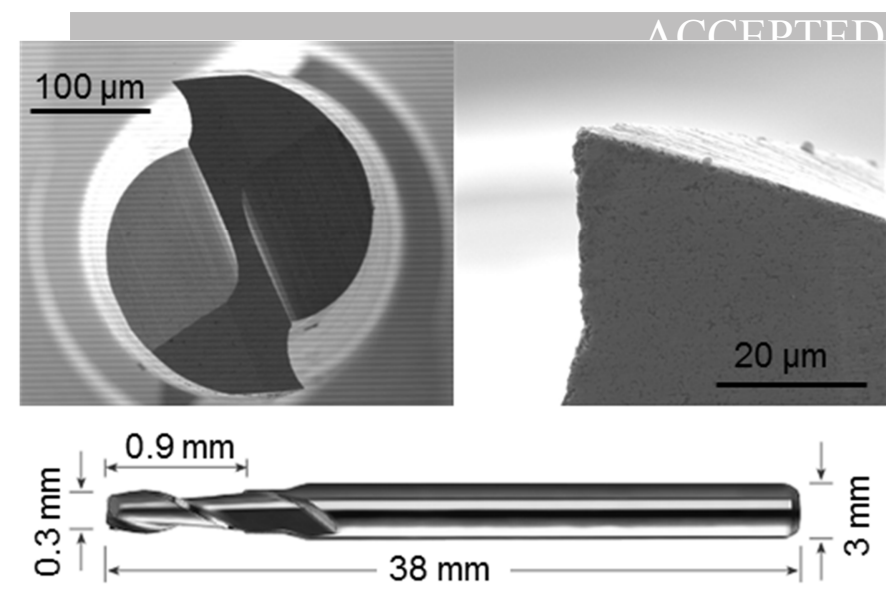

Fig. 4. SEM image of a fresh tool and its main dimensions

\subsection{Surface integrity analysis}

The integrity of the machined surfaces was evaluated in terms of topography characteristics, surface defects, metallurgical state and mechanical properties. The machined workpieces were first prepared by gentle cleaning in an ultrasonic bath in order to remove residual chips particles.

The surface topography was first qualitatively assessed through SEM analysis and then sampled by using a Sensofar ${ }^{\mathrm{TM}}$ PL $\mu$ Neox confocal optical profiler at regular distances from the border of the workpiece, namely $12.5 \mathrm{~mm}$. The instrument was equipped with a 100x lens characterized by a field of view of $127 \times 97 \mu \mathrm{m}^{2}$ and a vertical resolution of about $5 \mathrm{~nm}$. The roughness was evaluated following the ISO 25178 standard and the arithmetic mean value Ra was used to quantify the surface quality of the machined surfaces. The profile analysis was performed using cut-off values $\lambda_{c}$ of $0.25 \mathrm{~mm}$ or $0.8 \mathrm{~mm}$ in a number of 5 . To this end, respectively $21 \mathrm{x} 1$ and $51 \times 1$ stitched images with $25 \%$ of overlap were acquired along the bottom of the slots, close to the middle in order to avoid the entrance and exit areas. Average Ra values were calculated on the basis of 10 different profiles.

The SEM analysis of the machined surfaces permitted also to evaluate the presence and dimension of surface damages as well as the extension of the burrs.

The samples were then metallographically prepared and etched with the Kroll's reagent to analyze their metallurgical state by using both optical and scanning electron microscopy.

Finally, the mechanical properties of the micro-milled specimens were analyzed by nano-indentation tests using a Berkovic tip. Preliminary tests were performed in order to choose the appropriate load and dwell time as suggested in (Lucca et al., 2010). In particular, the load and the dwell were respectively ranged from 5 to $150 \mathrm{mN}$ and from 2 up to $100 \mathrm{~s}$. The values that allow achieving stable nano-hardness results and avoiding creep effect were found to be $50 \mathrm{mN}$ and $10 \mathrm{~s}$. The indentations were performed from the top surface toward the bulk material. Five measurements were taken for each depth, with measurement locations well-spaced to avoid interference between indentations.

\section{Results and discussion}

\subsection{Surface topography and burrs}

The roughness plots of the slots bottom surfaces as a function of the cutting parameters under dry and MQL conditions are shown in Fig. 5, and related SEM images and profiler scans are in Fig. 6. As expected, the lowest feed rate causes an evident surface damage, being the ploughing mechanism predominant over the shearing. As the feed rate increases, the surface quality becomes lower, and not acceptable for finishing cutting at the highest investigated feed rate. From the analysis of Figs. 5 and 6 it is clear that for the intermediate feed rates a comparable surface quality can be achieved under dry and MQL cutting conditions. In case of MQL the influence of the cutting speed is negligible, whereas for dry cutting the best surface finish is obtained at the lowest investigated cutting speed. 


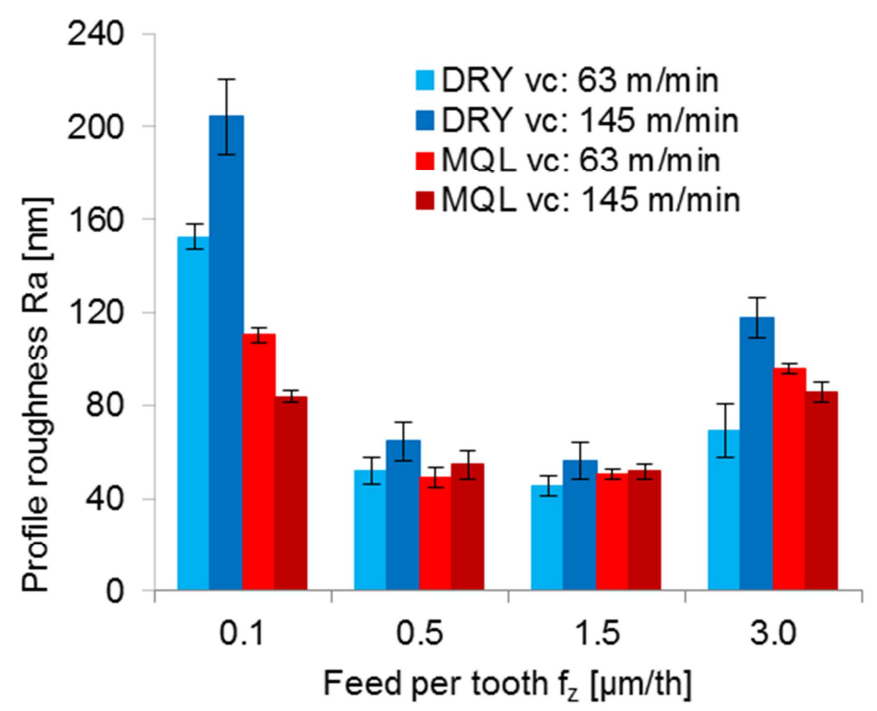

Fig. 5. Machined surface roughness as a function of the cutting parameters under dry and MQL conditions

A qualitative analysis of the burrs formation was carried out through SEM inspection. Fig. 7 gives a view of the top burrs (Poissontype (da Silva et al., 2015) for intermediate feed rates and the lowest cutting speed under dry and MQL conditions. At the feed of 0.5 $\mu \mathrm{m} /$ tooth under both dry and MQL conditions, ploughing prevails on shearing and the consequent plastic deformation causes the burrs to be larger than at $1.5 \mu \mathrm{m} /$ tooth. On the contrary, at the feed of $1.5 \mu \mathrm{m} /$ tooth, dry cutting provokes a slightly less amount of burrs, which are also more regularly developed, in comparison to MQL cutting. Similar phenomena were observed for the cutting speed of 145 $\mathrm{m} / \mathrm{min}$. We can also appreciate the different shape of the burrs as a function of the machining strategy, namely down-milling or upmilling. When down-milling is applied, the burrs result to be thinner, thus ensuring their easier removal after cutting (Piquard et al., 2014).
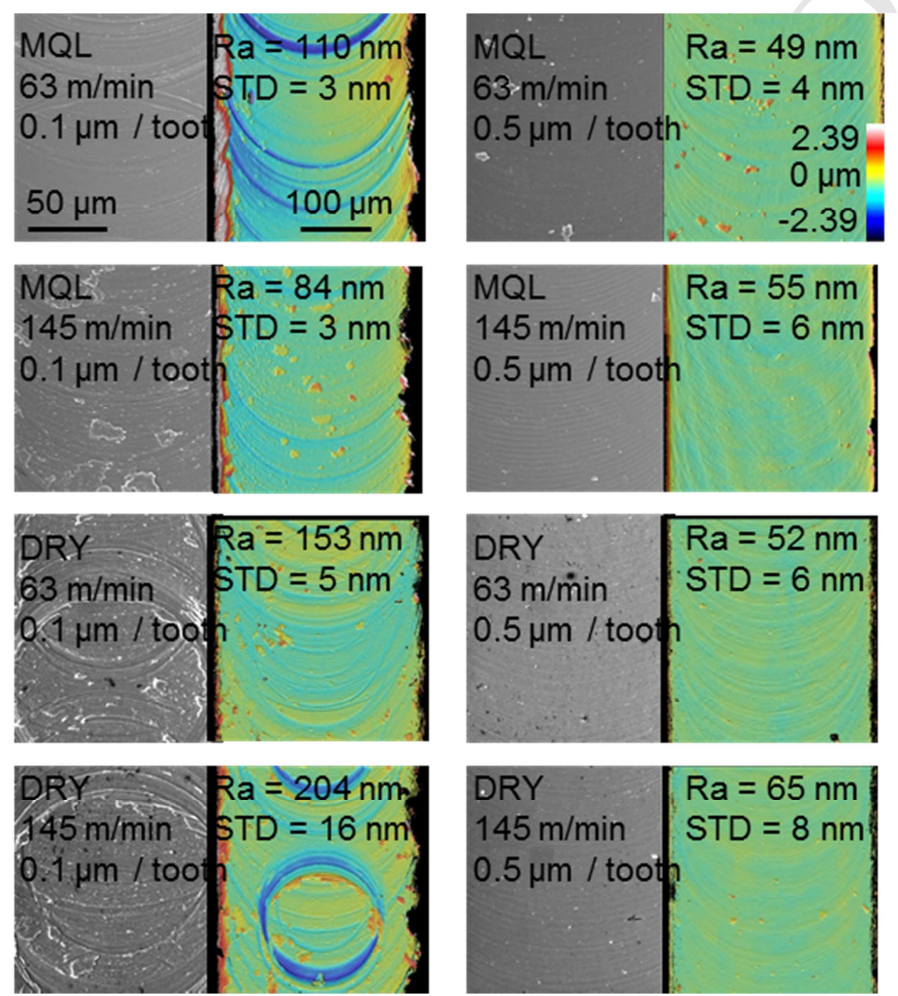
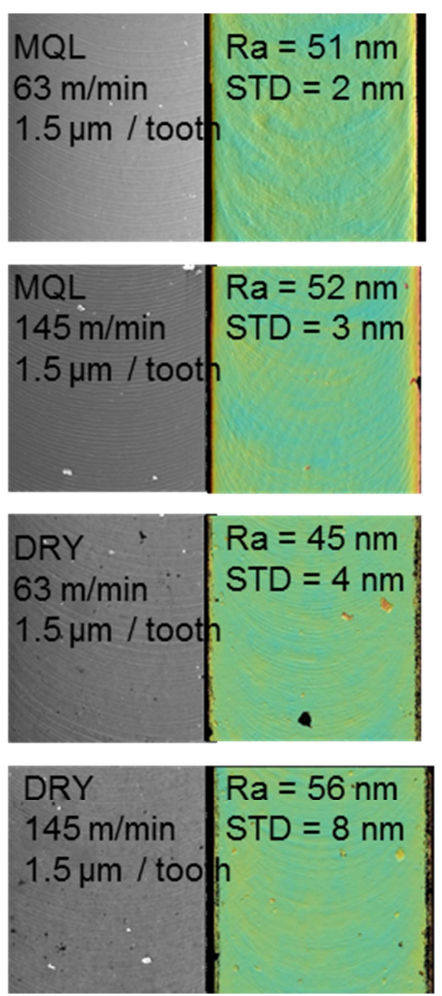
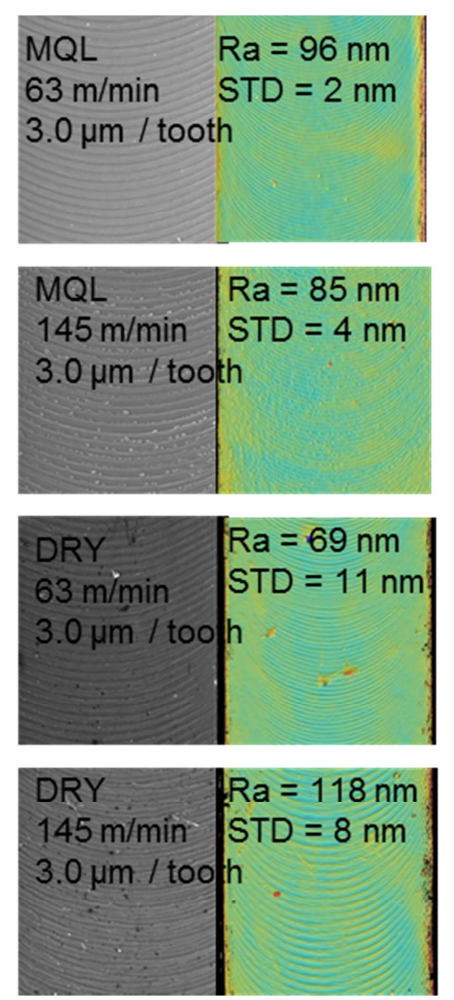

Fig. 6. Topographies of the slots bottom surfaces at varying cutting parameters under dry and MQL conditions (SEM images and optical profiler scans) 


\section{ACCEPTED MANUSCRIPT}

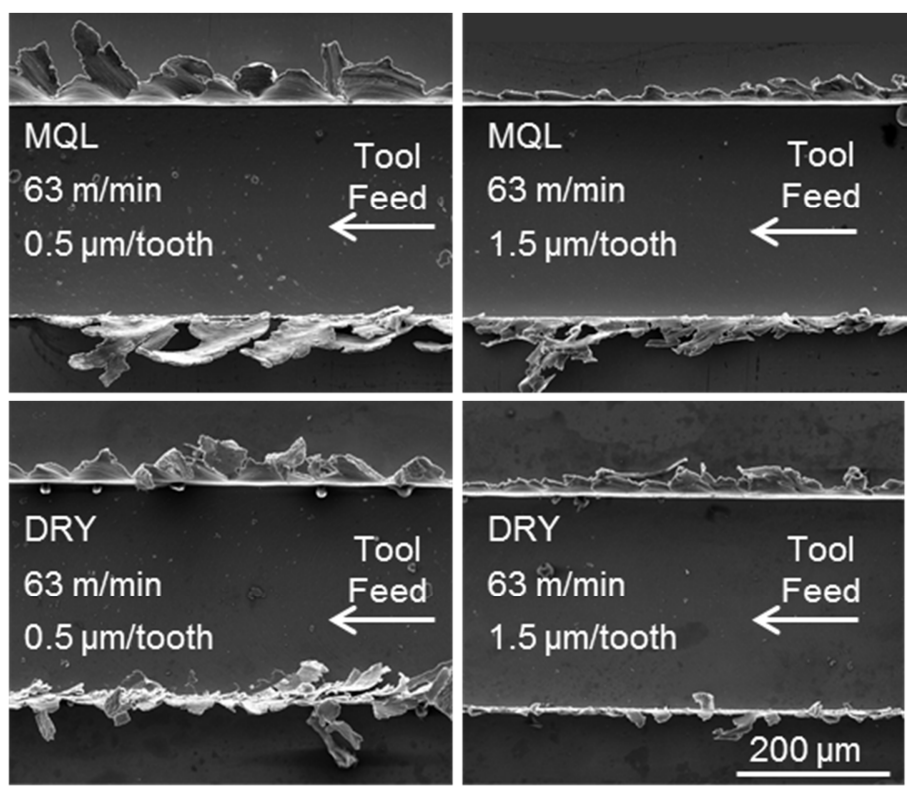

Fig. 7. View of the top burrs (dry and MQL, $\mathrm{V}_{c}=63 \mathrm{~m} / \mathrm{min}$ )

\subsection{Microstructural alterations}

Fig. 8A shows the optical image (acquired through a Leica microscope at magnification of 200x) of the microstructure of the slot cross-section in case of dry condition, when using a cutting speed of $63 \mathrm{~m} / \mathrm{min}$ and a feed of $1.5 \mu \mathrm{m} /$ tooth. No microstructural alterations in terms of phase transformation and dynamic recrystallization can be appreciated, meaning that even without any cutting fluid the temperature rise due to cutting is not high enough to provoke a change in the material microstructural state. A closer examination of the slot sidewall microstructure by SEM analysis (Fig. 8B) reveals the presence of bent lamellae to an average depth of $5 \mu \mathrm{m}$, but without any kind of damaging induced by the cutting process, whereas this kind of distortion is not present at the slot bottom surface.

\subsection{Nano-hardness}

The hardness of the samples after EBM was $4.34 \pm 0.43 \mathrm{GPa}$. In the micro-milled samples, a 15-20 $\mu \mathrm{m}$ sub-surface layer of high hardness was observed, with a peak value of $6.5 \mathrm{GPa}$. Fig. 9A shows the force-penetration depth curves for the samples processed through dry machining at different cutting speeds and fixed feed per tooth compared with the one of the asreceived sample. The maximum penetration depth decreases when the cutting speed increases, and the slope of the unloading curve increases. This can be attributed to the presence of lamellae that are bent by plastic deformation. In dry cutting (Fig. 9B), the hardness increases up to $6.5 \mathrm{GPa}$ in the zone close to the machined surface for the highest cutting speed and feed per tooth, and decreases when the feed per tooth decreases. Similar results were observed for surfaces machined under MQL condition, but with slightly lower hardness values (Fig. 10). This difference between dry and MQL conditions is more evident at the highest cutting speed as shown in Fig. 10B.

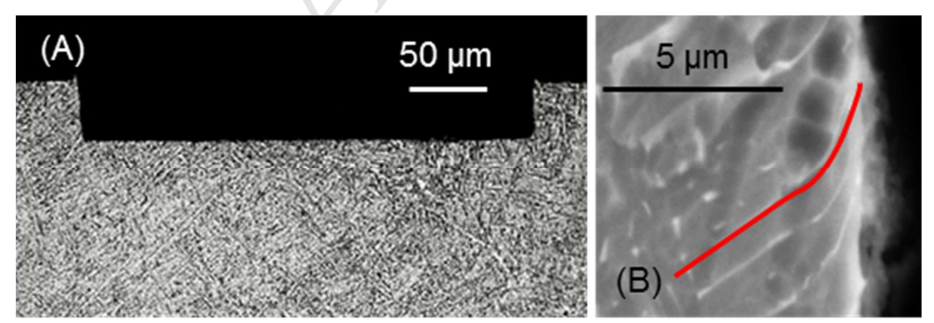

Fig. 8. Microstructure of the slot cross-section (A), and SEM detail of the slot sidewall sub-surface (B) (dry, $\mathrm{v}_{\mathrm{c}}=63 \mathrm{~m} / \mathrm{min}, \mathrm{f}_{\mathrm{z}}=1.5 \mu \mathrm{m} /$ tooth) 

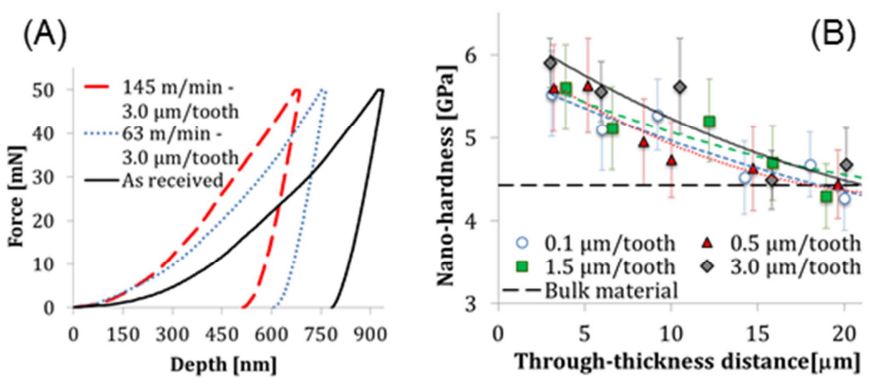

Fig. 9. Force vs. penetration depth curves for Berkovich indentations (A); nano-hardness of samples dry micro-milled at $145 \mathrm{~m} / \mathrm{min}$ (B)

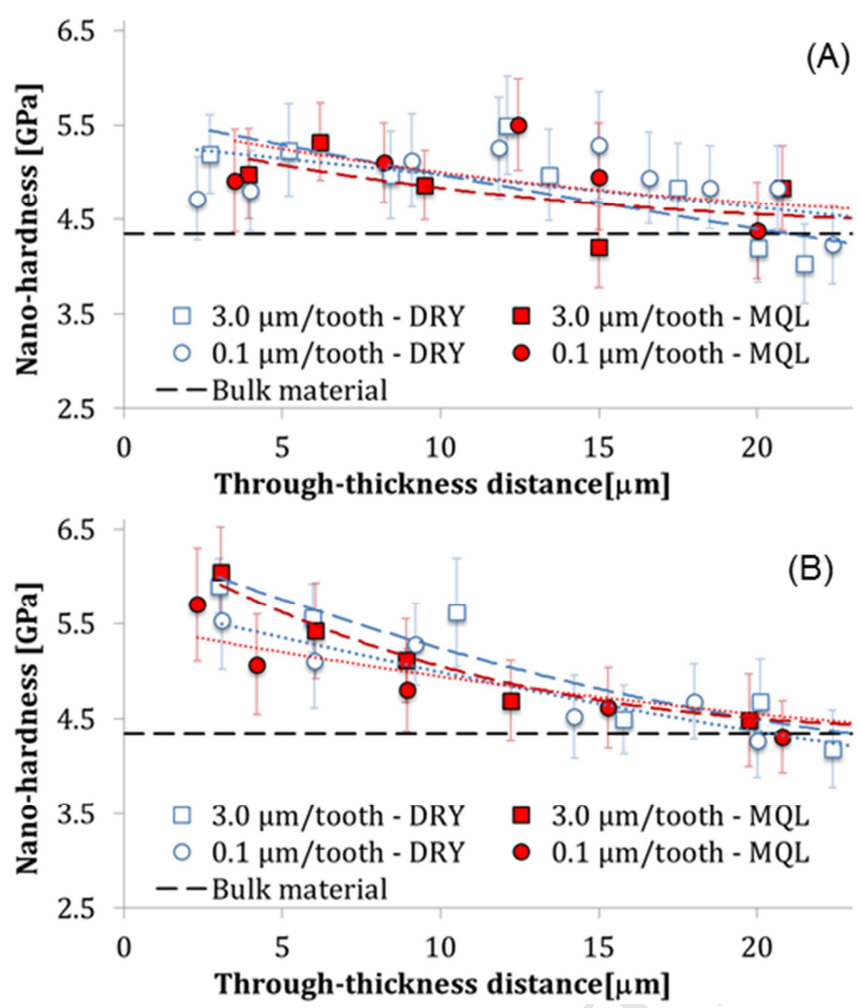

Fig. 10. Nano-hardness profiles through thickness distance for samples dry and MQL machined at (A) 63, and (B) $145 \mathrm{~m} / \mathrm{min}$

\subsection{Surface defects}

The surface defects found at the bottom of slots after machining experiments are similar regardless the lubrication condition, namely dry or MQL. For the lowest feed per tooth a high amount of surface defects is present, being the whole surface affected by their presence as a consequence of the ploughing mechanism that prevails at the lowest feed per tooth. On the contrary, a minimal amount of surface defects can be appreciated for the feeds per tooth of 0.5 and $1.5 \mu \mathrm{m} /$ tooth, which are only characterized by the presence of some chip debris. When the feed per tooth is increased to $3.0 \mu \mathrm{m}$ the defects are more evident, as the presence of smeared material is evident. The surface defects at varying cutting parameters are shown in Fig. 11 and Fig. 12 in case of dry and MQL conditions, respectively.
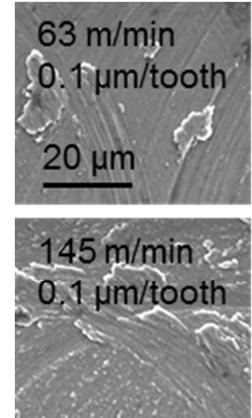
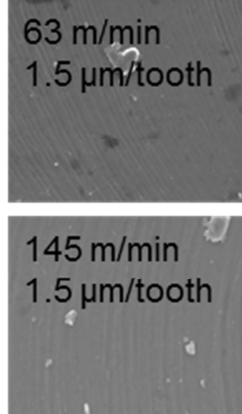

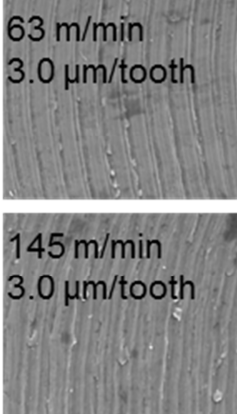


Fig. 11 Surface defects in the case of dry cutting condition at varying cutting parameters
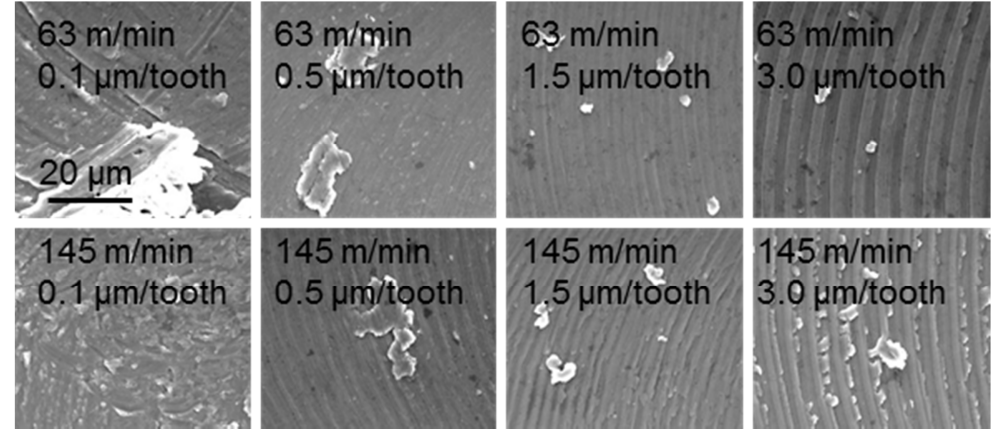

Fig. 12 Surface defects in the case of MQL lubrication condition at varying cutting parameters

\subsection{Tool analysis}

As previously underlined, each tool was inspected through SEM before as well as after the machining process, to evaluate the state of the tool as a consequence of the cutting process and lubrication conditions. In the Fig. 13, it can be seen that, regardless the lubrication condition, there are some workpiece material adhered on the tool cutting edge. The EDS analysis proved the origin of the material presented on the cutting edge: Fig. 14 clearly demonstrates that the adhered material is titanium from the machined workpiece.

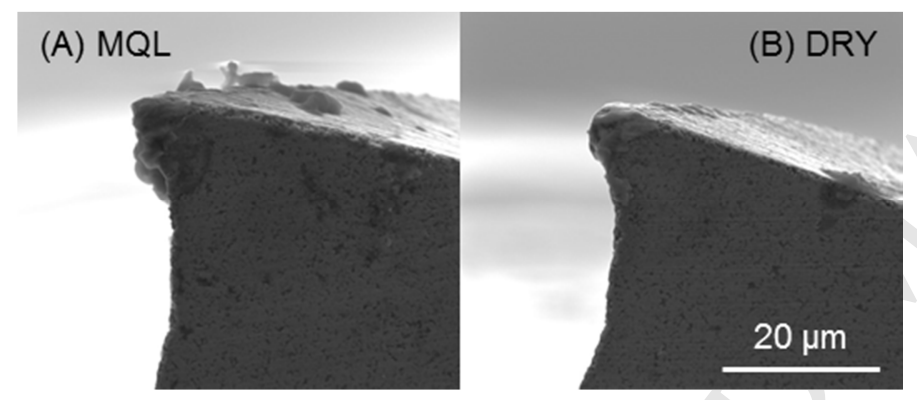

Fig. 13. SEM pictures the cutting edge state after machining at $v_{c}=63 \mathrm{~m} / \mathrm{min}$ and $\mathrm{f}_{\mathrm{z}}=1.5 \mathrm{um} /$ tooth

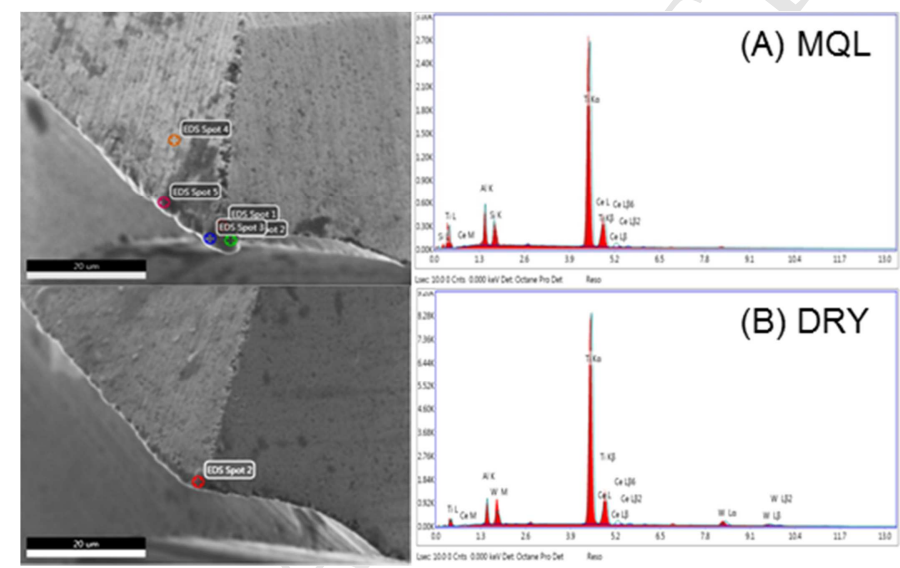

Fig. 14. Example of the EDS analysis of tools after machining under MQL and DRY lubrication condition $\left(\mathrm{v}_{\mathrm{c}}=63 \mathrm{~m} / \mathrm{min}\right.$ and fz $\left.=1.5 \mu \mathrm{m} / \mathrm{th}\right)$

\subsection{Cryogenic cooling}

The micro-milling tests under cryogenic cooling were carried out at those cutting parameters assuring the best performance in dry cutting, namely cutting speed of $63 \mathrm{~m} / \mathrm{min}$ and feed rate of $1.5 \mu \mathrm{m} /$ tooth. Fig. 15 shows the topography of the slot bottom surface machined under cryogenic cooling. In the same figure, the roughness profiles of the different cooling/lubrication conditions are compared. The surface quality for cryogenic cooling is comparable to that obtained for dry cutting and MQL. However, a slight increase of the surface roughness is evident, with a more perturbed roughness profile of higher amplitude. This can be ascribable to a larger amount of smeared material on the machined surface of the cryogenic sample, as confirmed by the SEM observations (see Fig. 16A). It is worth to note the fact that this phenomenon observed in 


\section{ACCEPTED MANUSCRIPT}

micro-machining is not in agreement with what observed in cryogenic conventional machining (Bordin et al., 2014). In Fig. $16 \mathrm{~B}$ and 17 the SEM image of the tool after cryogenic cutting is shown: as for the other lubrication conditions, workpiece material adhesion is evident, without any sign of damaging.

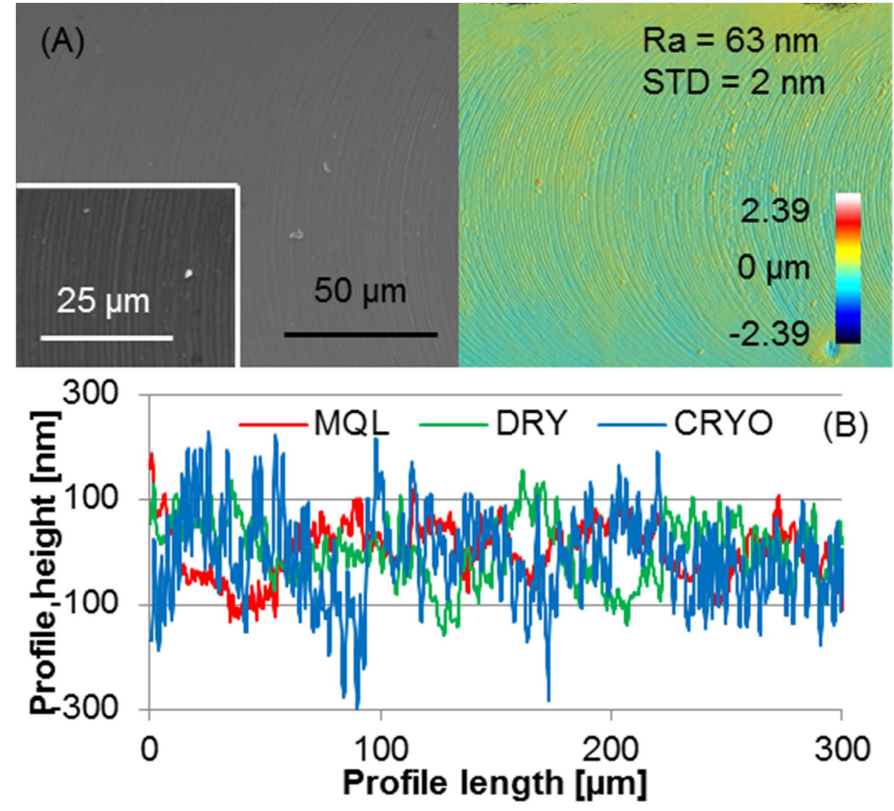

Fig. 15. Bottom surface of the slot machined under cryogenic condition ( $v_{c}=63 \mathrm{~m} / \mathrm{min}, \mathrm{f}_{\mathrm{z}}=1.5 \mu \mathrm{m} /$ tooth) (A); roughness profiles at varying lubrication conditions (B)

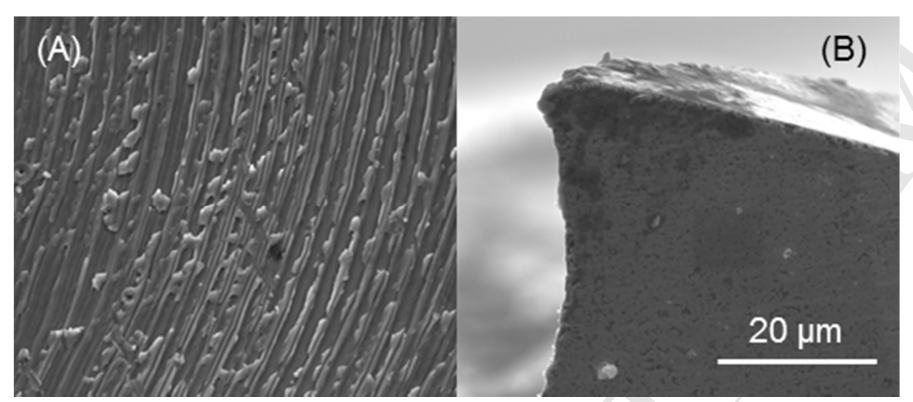

Fig. 16. Bottom surface defects (A) and tool state (B) after machining at cryogenic condition $\left(\mathrm{v}_{\mathrm{c}}=63 \mathrm{~m} / \mathrm{min}, \mathrm{f}_{\mathrm{z}}=1.5 \mu \mathrm{m} /\right.$ tooth)

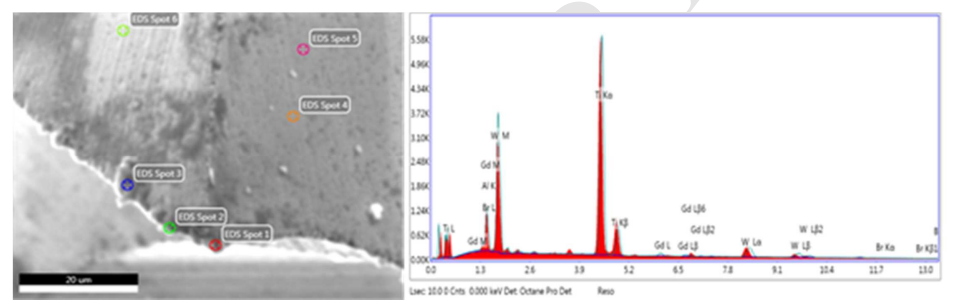

Fig. 17. Example of the EDS analysis of tools after machining under cryogenic lubrication condition $\left(\mathrm{v}_{\mathrm{c}}=63 \mathrm{~m} / \mathrm{min}\right.$ and fz $=1.5 \mu \mathrm{m} /$ th $)$

The analysis of the burrs under cryogenic cooling (Fig. 18A) evidences an improvement compared to dry cutting, with the presence of more uniform and less jagged burrs on both sides of the slot. As shown in Fig. 18B, the nano-hardness measured in cryogenic cooling is very close to that for dry cutting, being the microstructure in both cases very similar.
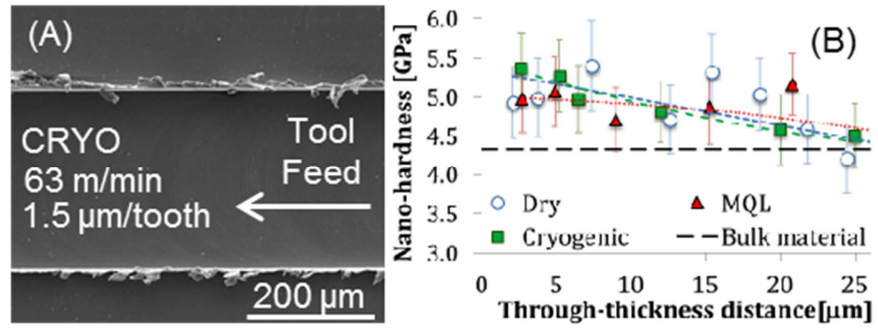
Fig. 18. View of the top burrs under cryogenic cooling $(A)$; nano-hardness profile through thickness distance at varying lubrication condition (B) $\left(\mathrm{V}_{\mathrm{c}}=63 \mathrm{~m} / \mathrm{min}, \mathrm{f}_{\mathrm{z}}=1.5 \mu \mathrm{m} /\right.$ tooth $)$

\section{Conclusions}

The performances of Minimum Quantity Lubrication (MQL), dry cutting and cryogenic cooling were evaluated when micromilling samples of Ti6Al4V obtained by the Additive Manufacturing Technology named Electron Beam Melting. The main findings can be summarized as follows:

- at intermediate feed rates the surface integrity characteristics of the machined samples are comparable under dry cutting and MQL;

- under cryogenic cooling conditions, the surface integrity improves, especially in terms of presence and quality of burrs, but with a slight worsening of the surface topography and increase of the surface defects;

- no alteration of the microstructure of the Ti6Al4V processed by EBM was observed for all the investigated cutting conditions.

The effect of the lubricating/cooling conditions seems less significant in micro-milling compared to the machining operations carried out at macro-scale: this can be ascribed to the fact that both the forces and the temperatures arising during micro-machining are much lower compared to conventional machining, making the effect of the cutting fluid less relevant (Yang et al., 2010).

The presented results clearly show that dry cutting assures a surface quality comparable to that obtained when MQL is used in micro-milling Ti6Al4V samples produced by EBM. On the other hand, the use of the cryogenic cooling does not improve to a significant extent the performances of the machining operations, which can justify its use. Furthermore, cryogenic cooling requires high investment costs, transportation of the liquid nitrogen and, above all, the liquid nitrogen production is quite an energy-intensive process, which increase the overall carbon footprint of cryogenic cooling. In the case of MQL, the cutting fluid consumption in the micro-milling center devoted to the present experimental campaign is in the order of $20 \mathrm{ml} / \mathrm{h}$, meaning an approximate consume of $40.3 \mathrm{l} /$ year (considering 8 working hours/day, 21working days/ month, 12 months), which can be fully saved in case of dry cutting, as well as its associated carbon foot print and energy necessary to produce, use and transport it. The employed MQL system uses paraffin oil as cutting fluid mixed with compressed air that is used also in dry cutting to cool down the interface between workpiece and tool and clear the chips from the cutting area. Therefore, being in the employed system the difference between MQL and dry cutting the sole use of the paraffin oil, the $\mathrm{CO}_{2}$ and energy consumption related to its use must be considered more in detail.

Paraffin oil is a mineral oil that consists of saturated hydrocarbons - alkanes and is produced through a refining process of the crude oil carried out in industrial sites characterized by very significant consumptions of energy and water as well as production of wastes and emissions. (Barthe et al., 2015)

The 2014 data report of the International Association of Oil \& Gas Producers (IOGP) (International Association of Oil\&Gas Producers, 2015) states that the quantities of emissions generated in the production (exploration, production and processing operations) of $1 \mathrm{~kg}$ of hydrocarbon include $134 \mathrm{~g}$ of carbon dioxide $\left(\mathrm{CO}_{2}\right)$, which means $5.4 \mathrm{~kg}$ of $\mathrm{CO}_{2}$ emissions for producing the average quantity of paraffin oil needed to run the micro-milling process for 1 year. The same report (International Association of Oil\&Gas Producers, 2015) states that $1.4 \mathrm{MJ}$ are needed to produce $1 \mathrm{~kg}$ of hydrocarbon, which means approximately $56.5 \mathrm{MJ}$ of energy consumption per year in the investigated case. Furthermore, additional $\mathrm{CO}_{2}$ emissions and energy consumption derive from the paraffin oil transportation from the production site to the machining shop floor: from the 2011 data of an EU report (EEA, 2012), which states that approximately $80 \mathrm{~g}$ of $\mathrm{CO}_{2}$ are emitted to the environment for the transport of $1 \mathrm{t}$ of goods for $1 \mathrm{~km}$ distance, .assuming an average distance of transportation of $60 \mathrm{~km}$, approximately $194 \mathrm{~g}$ of $\mathrm{CO}_{2}$ emissions per year due to the paraffin oil transportation will be avoided.

It is worth to underline that the use of dry cutting could increase the energy consumption, since the cutting forces may increase due an increase of the friction coefficient; nevertheless, additional cutting tests making use of a dynamometer for the forces measurements are necessary. 
Safety data sheets (SIGMA-ALDRICH, 2014) indicates the paraffin oil as a not hazardous substance, thus not requiring any special means of transportation and handling. Regarding the carcinogenicity, the paraffin oil belongs to the Group 1 - IARC: Carcinogenic to humans, implying that its disposal must be accomplished by a licensed company. However, in MQL systems implemented in micro-machining centres, the cutting fluid is not recovered, and the produced aerosol goes directly into the environment. Even if the amount of oil is very low, some particles are spread in the air, which, being inhaled, can led to lipid pneumonia. (SIGMA-ALDRICH, 2014)

From the above reported considerations, dry cutting represents the most suitable option to decrease the environmental impact of micro-machining applied to biomedical components, as no cutting fluids are used, with the consequent elimination of the related health hazards, as well as the components cleaning steps after machining can be significantly reduced, thus not only lowering the overall production costs but also the environmental impact of the whole process chain. Future works will include the measurements of the cutting forces and temperatures in order to provide an analytical model of the process under the different lubricating/cooling conditions, as well as a comprehensive economic analysis of the process that will take into account the added costs that may eventually arise in case of a reduced tool life when dry cutting is applied.

\section{References}

Afazov, S.M., Zdebski, D., 2013. Effects of micro-milling conditions on the cutting forces and process stability. J. Mater. ... 213, 671-684. doi:10.1016/j.jmatprotec.2012.12.001

Arcam, n.d. Ti6Al4V Titanium Alloy [WWW Document]. URL http://www.arcam.com/technology/electron-beammelting/materials/ (accessed 5.7.15).

Barthe, P., Chaugny, M., Roudier, S., Sancho, L.D., 2015. Best Available Techniques (BAT) Reference Document for the Refining of Mineral Oil and Gas. doi:10.2791/010758

Bartolo, P., Kruth, J.-P., Silva, J., Levy, G., Malshe, A., Rajurkar, K., Mitsuishi, M., Ciurana, J., Leu, M., 2012. Biomedical production of implants by additive electro-chemical and physical processes. CIRP Ann. - Manuf. Technol. 61, 635-655. doi:10.1016/j.cirp.2012.05.005

Bordin, A., Bruschi, S., Ghiotti, A., Bucciotti, F., Facchini, L., 2014. Comparison between wrought and EBM Ti6Al4V machinability characteristics. Key Eng. Mater. 611-612, 1186-1193. doi:10.4028/www.scientific.net/KEM.611612.1186

Câmara, M. a., Rubio, J., Abrão, A.M., Davim, J.P., 2012. State of the Art on Micromilling of Materials, a Review. J. Mater. Sci. ... 28, 673-685. doi:10.1016/S1005-0302(12)60115-7

da Silva, L.C., da Mota, P.R., da Silva, M.B., Ezugwu, E.O., Machado, Á.R., 2015. Study of burr behavior in face milling of PH 13-8 Mo stainless steel. CIRP J. Manuf. Sci. Technol. 8, 34-42. doi:10.1016/j.cirpj.2014.10.003

Debnath, S., Reddy, M.M., Yi, Q.S., 2014. Environmental friendly cutting fluids and cooling techniques in machining: a review. J. Clean. Prod. 83, 33-47. doi:10.1016/j.jclepro.2014.07.071

Dhanorker, A., Liu, X., Özel, T., 2007. Micromilling Process Planning and Modeling for Micromold Manufacturing. ASME 2007 Int. Manuf. Sci. Eng. Conf. 759-769. doi:10.1115/MSEC2007-31070

Dornfeld, D., Min, S., Takeuchi, Y., 2006. Recent Advances in Mechanical Micromachining. CIRP Ann. - Manuf. Technol. 55, 745-768. doi:10.1016/j.cirp.2006.10.006

EEA, 2012. Specific CO2 emissions per tonne-km and per mode of transport in Europe, 1995-2011 [WWW Document]. Eur. Environ. Agency Maps graphs. URL http://www.eea.europa.eu/data-and-maps/figures/specific-co2-emissions-pertonne-2 
Facchini, L., 2010. Microstructure and mechanical properties of biomedical alloys produced by Rapid Manufacturing techniques. Univeristy of Trento, Italy.

Facchini, L., Magalini, E., Robotti, P., Molinari, A., 2009. Microstructure and mechanical properties of Ti-6Al-4V produced by electron beam melting of pre-alloyed powders. Rapid Prototyp. J. 15, 171-178. doi:10.1108/13552540910960262

Filiz, S., Conley, C.M., Wasserman, M.B., Ozdoganlar, O.B., 2007. An experimental investigation of micro-machinability of copper 101 using tungsten carbide micro-endmills. Int. J. Mach. Tools Manuf. 47, 1088-1100. doi:10.1016/j.ijmachtools.2006.09.024

International Association of Oil\&Gas Producers, 2015. Environmental performance indicators - 2014 data.

Jawahir, I.S., Brinksmeier, E., M’Saoubi, R., Aspinwall, D.K., Outeiro, J.C., Meyer, D., Umbrello, D., Jayal, a. D., 2011. Surface integrity in material removal processes: Recent advances. CIRP Ann. - Manuf. Technol. 60, 603-626. doi:10.1016/j.cirp.2011.05.002

Kaynak, Y., Lu, T., Jawahir, I.S., 2014. Cryogenic Machining-Induced Surface Integrity: A Review and Comparison with Dry, MQL, and Flood-Cooled Machining. Mach. Sci. Technol. 18, 149-198. doi:10.1080/10910344.2014.897836

Kuram, E., Ozcelik, B., 2013. Multi-objective optimization using Taguchi based grey relational analysis for micro-milling of Al 7075 material with ball nose end mill. Measurement 46, 1849-1864. doi:10.1016/j.measurement.2013.02.002

Lai, X., Li, H., Li, C., Lin, Z., Ni, J., 2008. Modelling and analysis of micro scale milling considering size effect, micro cutter edge radius and minimum chip thickness. Int. J. Mach. Tools Manuf. 48,1-14. doi:10.1016/j.ijmachtools.2007.08.011

Lawal, S.A., Choudhury, I.A., Nukman, Y., 2013. A critical assessment of lubrication techniques in machining processes: A case for minimum quantity lubrication using vegetable oil-based lubricant. J. Clean. Prod. 41, 210-221.

doi:10.1016/j.jclepro.2012.10.016

Li, K.M., Chou, S.Y., 2010. Experimental evaluation of minimum quantity lubrication in near micro-milling. J. Mater. Process. Technol. 210, 2163-2170. doi:10.1016/j.jmatprotec.2010.07.031

Liu, X., DeVor, R.E., Kapoor, S.G., 2006. An Analytical Model for the Prediction of Minimum Chip Thickness in Micromachining. J. Manuf. Sci. Eng. 128, 474. doi:10.1115/1.2162905

Lucca, D. a., Herrmann, K., Klopfstein, M.J., 2010. Nanoindentation: Measuring methods and applications. CIRP Ann. - Manuf. Technol. 59, 803-819. doi:10.1016/j.cirp.2010.05.009

Marcon, a., Melkote, S., Kalaitzidou, K., Debra, D., 2010. An experimental evaluation of graphite nanoplatelet based lubricant in micro-milling. CIRP Ann. - Manuf. Technol. 59, 141-144. doi:10.1016/j.cirp.2010.03.083

Mian, A.J., Driver, N., Mativenga, P.T., 2010. A comparative study of material phase effects on micro-machinability of multiphase materials. Int. J. Adv. Manuf. Technol. 50, 163-174. doi:10.1007/s00170-009-2506-9

Munoz, A., Sheng, P., 1995. Analytical Approach for Determining the Environmental Impact of Machining Processes. J. Mater. Process. Technol. 53, 736-758.

Murr, L.E., Esquivel, E.V., Quinones, S. a., Gaytan, S.M., Lopez, M.I., Martinez, E.Y., Medina, F., Hernandez, D.H., Martinez, E., Martinez, J.L., Stafford, S.W., Brown, D.K., Hoppe, T., Meyers, W., Lindhe, U., Wicker, R.B., 2009. Microstructures and mechanical properties of electron beam-rapid manufactured Ti-6Al-4V biomedical prototypes compared to wrought Ti-6Al-4V. Mater. Charact. 60, 96-105. doi:10.1016/j.matchar.2008.07.006

Özel, T., Liu, X., Dhanorker, A., 2007. Modelling and simulation of micro-milling process. ... Exhib. Des. Prod. ....

Özel, T., Thepsonthi, T., Ulutan, D., Kaftanoğlu, B., 2011. Experiments and finite element simulations on micro-milling of Ti6Al-4V alloy with uncoated and cBN coated micro-tools. CIRP Ann. - Manuf. Technol. 60, 85-88.

doi:10.1016/j.cirp.2011.03.087 
Piquard, R., D'Acunto, A., Dudzinski, D., 2014. Study of burr formation and phase transformation during micro-milling of NiTi alloys, in: Proceedings of the 11th Internation Conference on High Speed Machining. Prague.

Sarıkaya, M., Güllü, A., 2015. Multi-response optimization of minimum quantity lubrication parameters using Taguchi-based grey relational analysis in turning of difficult-to-cut alloy Haynes 25. J. Clean. Prod. 91, 347-357. doi:10.1016/j.jclepro.2014.12.020

Shokrani, a., Dhokia, V., Newman, S.T., 2012. Environmentally conscious machining of difficult-to-machine materials with regard to cutting fluids. Int. J. Mach. Tools Manuf. 57, 83-101. doi:10.1016/j.ijmachtools.2012.02.002

SIGMA-ALDRICH, 2014. Safety data sheet [WWW Document]. URL http://www.sigmaaldrich.com/MSDS/MSDS/DisplayMSDSPage.do?country=GB\&language=en\&productNumber=1851 2\&brand=SIAL\&PageToGoToURL=/safety-center.html

Thepsonthi, T., Özel, T., 2013. Experimental and finite element simulation based investigations on micro-milling Ti-6Al-4V titanium alloy: Effects of cBN coating on tool wear. J. Mater. Process. Technol. 213, 532-542. doi:10.1016/j.jmatprotec.2012.11.003

Thepsonthi, T., Özel, T., 2012. Multi-objective process optimization for micro-end milling of Ti-6Al-4V titanium alloy. Int. J. Adv. Manuf. Technol. 63, 903-914. doi:10.1007/s00170-012-3980-z

Ulutan, D., Ozel, T., 2011. Machining induced surface integrity in titanium and nickel alloys: A review. Int. J. Mach. Tools Manuf. 51, 250-280. doi:10.1016/j.ijmachtools.2010.11.003

Umbrello, D., Micari, F., Jawahir, I.S., 2012. The effects of cryogenic cooling on surface integrity in hard machining: A comparison with dry machining. CIRP Ann. - Manuf. Technol. 61, 103-106. doi:10.1016/j.cirp.2012.03.052

Vazquez, E., Gomar, J., Ciurana, J., Rodríguez, C. a., 2015. Analyzing effects of cooling and lubrication conditions in micromilling of Ti6Al4V. J. Clean. Prod. 87, 906-913. doi:10.1016/j.jclepro.2014.10.016

Yang, K., Liang, Y., Zheng, K., Bai, Q., Chen, W., 2010. Tool edge radius effect on cutting temperature in micro-end-milling process. Int. J. Adv. Manuf. Technol. 52, 905-912. doi:10.1007/s00170-010-2795-z 


\section{HIGHLIGHTS}

- Micro-milling of EBM Ti6Al4V was carried out under MQL, dry and cryogenic condition

- Different cutting speeds and feed rates were utilized

- Surface quality and burrs formations are mainly influenced by the feed per tooth

- The lubrication condition weakly influences the cutting perfomances 